\title{
Anxiety Sensitivity and Panic Symptomatology: The Mediator Role of Hypochondriacal Concerns
}

\author{
Carmen Berrocal ${ }^{1}$, Francisca Ruiz Moreno ${ }^{2}$, and Josefina Cano ${ }^{1}$ \\ ${ }^{1}$ Universidad de Málaga (Spain) \\ ${ }^{2}$ Instituto de Psicología y Psiquiatría de Málaga (Spain)
}

\begin{abstract}
The present study tests the mediating role of hypochondriasis to explain the relation between anxiety sensitivity and panic symptomatology. Fifty-seven outpatients with clinically significant levels of panic symptomatology were selected to participate in the study. Measures of anxiety sensitivity, hypochondriasis, and panic symptomatology were obtained from standardized, selfadministered questionnaires: the Anxiety Sensitivity Index (ASI; Reiss, Peterson, Gursky, \& McNally, 1986), the Whiteley Index of Hypochondriasis (WI; Pilowsky, 1967), and the PanicAgoraphobic Spectrum Self-Report (PAS-SR; Cassano et al., 1997; Shear et al., 2001). Regression analyses were performed to test for the mediation models. The results show that the effect of anxiety sensitivity on panic symptomatology is not significant when controlling the hypochondriacal concerns, whereas the latter predicted panic symptoms. This result holds for the overall ASI as well as for the Physical Concerns and the Mental Incapacitation Concerns dimensions of the ASI scale. No evidence of a direct relation between the Social Concerns dimension and panic symptoms was found. The findings suggest that hypochondriacal concerns might represent the mechanism through which anxiety sensitivity is able to influence panic symptoms.
\end{abstract}

Keywords: anxiety sensitivity, hypochondriacal concerns, panic-agoraphobic symptomatology, mediators

\begin{abstract}
El objetivo del presente estudio es explorar el papel mediador de las preocupaciones hipocondríacas para explicar la relación entre la sensibilidad a la ansiedad y la sintomatología de pánico. Un total de 57 pacientes con niveles clínicamente significativos de sintomatología de pánico fueron seleccionados para participar en el estudio. Se han obtenido medidas de la sensibilidad a la ansiedad, mediante el Anxiety Sensitivity Index (ASI; Reiss, Peterson, Gursky, \& McNally, 1986), la sintomatología de pánico, mediante la subescala Panic-like-symptoms del Panic-Agoraphobic Spectrum Self-Report (PAS-SR; Cassano et al., 1997; Shear et al., 2001), e hipocondríasis mediante el Whiteley Index of Hypochondriasis (WI, Pilowsky, 1967) y la subsescala IIIness-related Phobia del PAS-SR. Se han llevado a cabo análisis de regresión para poner a prueba los modelos mediacionales. Los resultados obtenidos indican que el efecto de la sensibilidad a la ansiedad sobre la sintomatología de pánico no es significativo cuando se controlan las puntuaciones en hipocondríasis, si bien ésta última variable predice las puntuaciones en pánico. Dichos resultados se han obtenido sea para las puntuaciones totales en el ASI que para dos de las dimensiones que conforman la escala: preocupaciones relativas a problemas físicos y preocupaciones relativas a problemas mentales. La dimensión del ASI relacionada con preocupaciones de carácter social no se asocia con la sintomatología de pánico. Los resultados sugieren que las preocupaciones hipocondríacas podrían representar el mecanismo a través del cual la sensibilidad a la ansiedad ejerce un efecto sobre los síntomas de pánico.

Palabras clave: sensibilidad a la ansiedad, preocupaciones hipocondríacas, sintomatología de pánico-agorafobia, variables mediadoras
\end{abstract}

Correspondence concerning this article should be addressed to Carmen Berrocal. Profesora Asociada de Psicología, Departamento de Personalidad, Evaluación y Tratamientos Psicológicos, Facultad de Psicología Universidad de Málaga, Campus de Teatinos, s/n, Málaga-29071, Spain. Phone: +34 952132553; Fax: +34 952131101. E-mail: cberrocal@uma.es 
The present study examines the relation between anxiety sensitivity and hypochondriacal concerns among patients with panic symptomatology. Panic disorder has been recognized as a chronic disease with little spontaneous improvement and high rates of relapse after remission (Keller et al., 1994). Converging evidence indicates that panic symptomatology may also co-occur with other Axis I disorders affecting the presentation, course, and response to treatment of the major conditions (Feske et al., 2000; Frank et al., 2000, 2002; Noyes, Woodman, Bodkin, \& Yagla, 2004).

A number of variables have been involved in the psychopathology of panic. In particular, both anxiety sensitivity and hypochondriacal concerns play a central role in the major psychological theories of panic. Anxiety sensitivity refers to an excessive fear of bodily and anxietyrelated sensations, based on beliefs that these sensations are harmful (Reiss, 1987, 1991). Empirical data indicate that subjects with panic disorder score more highly on measures of anxiety sensitivity than subjects with other anxiety disorders (Taylor \& Cox, 1998; Taylor, Koch, \& McNally, 1992). Anxiety sensitivity also proved to predict panic symptoms in response to challenges that induced uncomfortable somatic sensations (Messenger \& Shean, 1998). Furthermore, the belief that bodily sensations have harmful consequences has been found to be a reliable predictor of panic attacks in both clinical and nonclinical populations (Maller \& Reiss, 1992; Schmidt, Lerew, \& Jackson, 1997, 1999).

In the same line, hypochondriacal beliefs and fears proved to be common among patients with panic disorder, and have been found to characterize a group of these patients before the onset of the disorder (Fava, Grandi, \& Canestrari, 1988; Fava, Grandi, Rafanelli, \& Canestrari 1992; Furer, Walker, Chartier, \& Stein, 1997; Perugi et al., 1998).

Although the association of panic symptomatology with hypochondriasis and anxiety sensitivity is well established, little is known about the specific pattern of interrelationships between the two predictors to affect the development of panic. It may be hypothesized that anxiety sensitivity and hypochondriacal fears have independent main effects on panic, but additional models may also be suggested. In particular, there is evidence for applying a mediational model to account for the relationships between the three variables of interest-anxiety sensitivity, hypochondriasis, and panic. In a mediational model, a mediator variable represents the causal mechanism through which a predictor influences a dependent variable (Baron \& Kenny, 1986). Applied to the issue of this paper, it may be hypothesized that hypochondriacal concerns mediate the relation between anxiety sensitivity (predictor) and panic symptomatology (dependent variable).

The introduction of a mediation model in a specific field is recommended in the case of accumulated data indicating the existence of a strong and consistent relation between a predictor and a criterion (Baron \& Kenny, 1986), as it is the case for the documented relation between anxiety sensitivity and panic. In addition, correlations between the predictor-anxiety sensitivity, in this study-and the hypothesized mediator-hypochondriacal concerns-are required to demonstrate mediation.

In this regard, a strong association between the two variables has also been reported, and the consideration of anxiety sensitivity as a temporal antecedent of change in hypochondriacal fears has been suggested previously. Thus, Otto, Pollack, Sachs and Rosenbaum (1992) found that, among a number of dimensions examined, anxiety sensitivity was the strongest predictor of hypochondriacal concerns in a sample of patients with panic disorders, as well as in a sample of patients with major depression without history of panic disorders (Otto, Demopulos, McLean, Pollack, \& Fava, 1998). Several additional studies have found that anxiety sensitivity is a risk factor for the development of hypochondriasis (Bravo \& Silverman, 2001; Watt \& Stewart, 2000).

Overall, the aforementioned lines of research led us to test in this study the possible mediating role of hypochondriasis to account for the relation between anxious expectation and panic symptomatology. While results from previous research provide a rationale to propose the mediational model, the empirical rationale to predict the specific character of such mediation-either complete or partial-has not yet been established, given that the model itself has not been previously tested. Therefore, the study may be characterized as exploratory.

\section{Method}

\section{Participants}

Participants were 57 outpatients with clinically significant levels of panic symptomatology. Subjects were recruited from three psychology and psychiatry clinics and two community mental health centers in the area of Malaga, Spain. They were selected from a larger sample of subjects consecutively presenting over a 6-month period to receive clinical assistance. Subjects who scored $\geq 35$ in the PanicAgoraphobic Self-Report (Cassano et al., 1999; Shear et al., 2001) were selected for participating in the study.

According to their principal diagnosis, $45.6 \%$ of the participants met the Diagnostic and Statistical Manual of Mental Disorders (4 ${ }^{\text {th }}$ edition, text revision; American Psychiatric Association, 2000) criteria for panic disorder with or without agoraphobia, $31.57 \%$ met criteria for affective disorders, $17.5 \%$ met criteria for other Axis I disorders, and the remaining $5.2 \%$ was not classified.

After providing informed consent, participants were asked to complete a questionnaire package for research purposes, which are described below. Additionally, participants were instructed to fill a form with general demographic data. 
All subjects were Caucasian, and thirty-eight (66.7\%) were women. Participants' age of ranged from 19 to 60 , with a mean age of 37.6 years $(S D=11.7)$. Around half $(45.6 \%)$ of the sample lived with a spouse or partner. Thirtyone per cent of the participants were unemployed and most $(69.9 \%)$ had received a high-school education or higher.

\section{Measures}

Measures of anxiety sensitivity, hypochondriasis, and panic symptomatology were obtained from standardized, self-administered questionnaires.

The Panic Agoraphobic Spectrum-Self Report (PAS-SR; Cassano et al., 1999; Shear et al., 2001; Spanish adaptation of Berrocal et al., 2006). This instrument was used to select the participants in the study as well as to measure variables of interest. It assesses the lifetime presence of a wide range of clinical features associated with panic-agoraphobic phenomenology. The instrument consists of 114 dichotomous items organized into eight domains: Separation Anxiety, Panic-like Symptoms, Stress Sensitivity, Substance and Medication Sensitivity, Anxious Expectation, Agoraphobia, Illness-related Phobia, and Reassurance Orientation. Paniclike Symptoms and Agoraphobia domains, in turn, include two sub-domains each: Typical and Atypical Symptoms. The questionnaire largely proved to feature good reliability and validity (Berrocal et al., 2006; Cassano et al., 1999; Shear et al., 2001). Panic spectrum scores $\geq 35$ have proved to be useful in predicting the response time to treatment in depression (Frank et al., 2000) and Bipolar I disorders (Frank et al., 2002). Additional data about the validity of this cut-off score have been reported (Shear et al. 2001).

Typical panic symptoms. The Panic Symptoms subscale of the PAS-SR was used to measure panic symptomatology. The subscale (14 items) explores the presence of the typical symptoms for a Panic Disorder with or without Agoraphobia according to the DSM-IV-TR (APA, 2000) or the International Classification of Diseases (ICD; World Health Organization, 1992) diagnostic criteria. Scoring on the Typical Panic Symptoms subscale of the PAS-SR does not take into account items of the PAS-SR assessing Illness-phobia.

Illness-related Phobia. In order to control the measurement error in the hypothesized mediator variable, multiple indicators of this construct were obtained. Therefore, the Illness-related Phobia subscale of the PAS-SR was used as an additional measure of hypochondriacal fears. Examples of items are: "Did you worry about... having a serious physical illness, when you heard about someone else who had it?" “...having a serious mental illness when you heard about someone else who had it? "...reading medical articles or hearing someone talk about medical topics?" Scoring on the Illness-related phobia subscale does not take into account items of the PASSR that measure panic symptoms.

Anxiety Sensitivity Index (ASI; Reiss, Peterson, Gursky, \& McNally, 1986; Spanish adaptation of Sandín, Chorot, \&
McNally, 1996). The ASI is a 16-item self-report inventory designed to assess the extent to which a patient believes that anxiety and its accompanying symptoms may lead to harmful physical, psychological, or social consequences. Respondents rate each item on a Likert-type scale ranging from 0 (very little) to 4 (very much). Examples of items are: "It scares me when I feel 'shaky' (trembling)," "It is important for me not to appear nervous;" "When I cannot keep my mind on a task, I worry that I might be going crazy." The inventory has a high degree of internal consistency, with alpha coefficients ranging from .82 to .91 , adequate split-half reliability, and satisfactory test-retest reliability over a 3-year interval (Maller \& Reiss, 1992; Peterson \& Heilbronner, 1987; Peterson \& Reiss, 1992). Several studies suggest that the anxiety sensitivity construct has a hierarchical structure, consisting of multiple lower order factors which load on a single higher order factor. In particular, evidence for three lower order factors has been found: Physical Concerns, Mental Incapacitation Concerns, and Social Concerns (Zinbarg, Brown, \& Barlow, 1997). Nevertheless, it is unclear whether the three factors are related to panic symptoms (Zinbarg, Brown, Barlow, \& Rapee, 2001).

The Whiteley Index of Hypochondriasis (WI; Pilowsky, 1967). The WI includes 14 dichotomous items assessing hypochondriacal concerns. Examples of items are: "If a disease is brought to your attention (through the radio, TV, newspapers, or someone you know), do you worry about getting it yourself?"; "Do you often worry about the possibility that you have a serious illness?"; "Is it hard for you to believe the doctor when he/she tells you there is nothing for you to worry about?"

Data from psychometric evaluations suggest that the questionnaire has good internal consistency (Speckens, Spinhoven, \& Sloekers, 1996) and test-retest reliability (Speckens, 2001).

\section{Statistical Analyses}

The statistical analyses were carried out using SPSS, version 11.5.

According to Baron and Kenny (1986), a set of three regression models is required to test for mediation. First, the mediation variable must be regressed on the independent variable; second, the dependent variable must be regressed on the independent variable; and third, the dependent variable must be regressed on both the independent variable and the mediator.

In this study, the dependent variable was the typicalpanic score of the PAS-SR. The three subscale scores of the ASI (i.e., Physical Concerns, Mental Incapacitation Concerns, and Social Concerns), as well as the overall index, were the independent variables. The measure of hypochondriasis was the mediator. Therefore, three regression models were estimated to test the relation between each predictor and the dependent variable when hypochondriasis scores were 
obtained with the WI. Then, three new regression models were estimated to test the relation between each predictor and panic symptoms but, in this case, with hypochondriasis scores obtained from the Illness-related Phobia domain of the PAS-SR.

To prove mediation, several conditions must be met (Baron \& Kenny, 1986): (a) in the first equation, the independent variable must affect the mediator; (b) in the second equation, the independent variable must be shown to affect the dependent variable; and, (c) in the third equation, the mediator must affect the dependent variable, whereas the effect of the independent variable on the dependent variable must be lower than in the second equation. Perfect mediation is revealed only if the independent variable has no effect when the mediator is added to the model. Partial mediation is revealed if the significant effect of the independent variable drops notably when the mediator is added to the model. Additionally, the Sobel test (MacKinnon, 1994; Sobel, 1990) was performed in order to carry out a formal assessment of the significance of the mediation.

\section{Results}

Table 1 shows the correlation coefficients, means, and standard deviations for the variables involved in the analyses. No significant correlations were found between the Social Concerns dimension of the ASI and either panic symptoms of the PAS-SR or the WI scores. All the remaining coefficients were positive and statistically significant $(p \leq$ $.01)$.

Table 2 presents the results for the regression analyses. The results indicate that the overall ASI is related in the expected direction to both hypochondriacal concerns- as measured by the WI-(Equation 1.1 in Table 2) and Typical
Panic symptoms (Equation 1.2). However, when hypochondriasis was added to the model (Equation 1.3), anxiety sensitivity failed to predict panic symptomatology, whereas hypochondriasis did. The mediator significantly decreased the effect of the predictor, supporting a model in which the hypochondriacal concerns strongly mediate the relation between anxiety sensitivity and panic symptoms.

At the level of the individual ASI dimensions, the results indicate that both the Physical Concerns and the Mental Incapacitation Concerns domains predict hypochondriasisas measured by the WI-(Equations 2.1 and 3.1) and panic symptoms (Equations 2.2 and 3.2). Again, when hypochondriasis is added to the models, the relationships between the ASI dimensions and panic symptoms are not significant, whereas hypochondriasis significantly predicts Panic Symptom scores (Equations 2.3. and 3.3). Even though ASI dimensions also contribute slightly to the model, when the mediator is included, their effect significantly decreases, supporting a model in which hypochondriacal concerns strongly mediate the relation between the Physical and Mental Incapacitation Concerns dimensions of the ASI and panic. Finally, the Social Concern scores failed to predict either the panic symptoms or the hypochondriasis scores (Equations 4.1 and 4.2).

The aforementioned pattern of results was replicated when the analyses were performed with the Illness-related Phobia subscale (see Table 3). The only exception was the result of the relation between the Social Concern dimension and hypochondriasis. The association between these two variables did not reach statistical significance when the analysis was carried out with the WI (Table 2, Equation 4.1). However, it was statistically significant when the equation was performed with the Illness-related Phobia subscale of the PAS (Table 3, Equation 4.1). Lastly, results from the Sobel test confirmed the statistical significance of the mediational pathways found through regression analyses.

Table 1

Bivariate Correlations, Means, and Standard Deviations for Major Variables $(N=57)$

\begin{tabular}{|c|c|c|c|c|c|c|}
\hline $\begin{array}{c}\text { ASI } \\
\text { Total Score }\end{array}$ & $\begin{array}{c}\text { ASI } \\
\text { Physical } \\
\text { Concerns }\end{array}$ & $\begin{array}{c}\text { ASI } \\
\text { Mental } \\
\text { Concerns }\end{array}$ & $\begin{array}{c}\text { ASI } \\
\text { Social } \\
\text { Concerns }\end{array}$ & WI & $\begin{array}{l}\text { Illness } \\
\text { phobia }\end{array}$ & $\begin{array}{c}\text { Panic } \\
\text { symptoms }\end{array}$ \\
\hline
\end{tabular}

ASI Total score

ASI-Physical Concerns $\quad .949$

ASI-Mental Concerns $\quad .854^{*} \quad .718^{*}$

ASI-Social Concerns $\quad .628^{*} \quad .445^{*} \quad .410^{*}$

WI $.576^{*} \quad .593^{*} \quad .476^{*}$

PAS-SR Illness Phobia $\quad .650 * \quad .671 * \quad .476^{*} \quad .369 * \quad .36 \%$

$\begin{array}{lllllll}\text { PAS-SR Panic symptoms } & .387 * & .369 * & .398 * & .140 & .493 * & .477 *\end{array}$

\begin{tabular}{llllllll} 
Mean \pm SD & $42.91 \pm 13.5$ & $22.08 \pm 8.4$ & $9.83 \pm 4.2$ & $11.00 \pm 3.0$ & $5.46 \pm 3.6$ & $2.15 \pm 1.7$ & $10.24 \pm 2.9$ \\
\hline
\end{tabular}

Note. WI: Whiteley Index of Hypochondriasis; ASI: Anxiety Sensitivity Index.

$* p \leq 0.01$, two-tailed. 
Table 2

Regression Analyses to Test the Mediator Role of Hypochondriacal Concerns (as Measured by the WI)

\begin{tabular}{|c|c|c|c|c|c|c|c|c|}
\hline Equation & Predictor & DV & $\beta$ & $t$ & $p$ & $R^{2}$ & $F_{(d f)}$ & Sobel test $(p)$ \\
\hline 1.1 & ASI-total score & WI & .576 & 4.780 & .000 & .31 & $22.853_{(1,46)}{ }^{*}$ & $2.370(.017)$ \\
\hline 1.2 & ASI-total score & Panic & .387 & 2.843 & .007 & .14 & $8.080_{(1,46)} *$ & \\
\hline \multirow[t]{2}{*}{1.3} & ASI-total score & Panic & .141 & .907 & $n s$ & .27 & $8.343_{(2,45)} * *$ & \\
\hline & WI & & .426 & 2.733 & .009 & & & \\
\hline 2.1 & ASI-Physical Concerns & WI & .593 & 4.990 & .000 & .33 & $24.897_{(1,46)}{ }^{* *}$ & $2.445(.014)$ \\
\hline 2.2 & ASI-Physical Concerns & Panic & .369 & 2.694 & .010 & .11 & $7.257_{(1,46)} *$ & \\
\hline \multirow[t]{2}{*}{2.3} & ASI-Physical Concerns & Panic & .106 & .666 & $n s$ & .23 & $8.088_{(2,45)} * *$ & \\
\hline & WI & & .444 & 2.800 & .008 & & & \\
\hline 3.1 & ASI-Mental Concerns & WI & .476 & 3.672 & .001 & .21 & $13.483_{(1,46)}$ ** & $2.268(.023)$ \\
\hline 3.2 & ASI-Mental Concerns & Panic & .398 & 2.940 & .005 & .14 & $8.645_{(1,46)} *$ & \\
\hline \multirow[t]{2}{*}{3.3} & ASI-Mental Concerns & Panic & .202 & 1.414 & $n s$ & .25 & $9.135_{(2,45)} * *$ & \\
\hline & WI & & .411 & 2.874 & .006 & & & \\
\hline 4.1 & ASI-Social Concerns & WI & .255 & 1.787 & $n s$ & .04 & $3.194_{(1,46)} n s$ & $0.086(.127)$ \\
\hline 4.2 & ASI-Social Concerns & Panic & .140 & .958 & $n s$ & .02 & $.918_{(1,46)} n s$ & \\
\hline \multirow[t]{2}{*}{4.3} & ASI-Social Concerns & Panic & .011 & .086 & $n s$ & .22 & $7.794_{(2,45)}$ & \\
\hline & WI & & .504 & 3.795 & & & & \\
\hline
\end{tabular}

Note. DV: dependent variable in the equation; ASI: Anxiety Sensitivity Index; WI: Whiteley Index of Hypochondriasis.

$* p \leq .01 . * p \leq .001$.

Table 3

Regression Analyses to Test the Mediator Role of Hypochondriacal Concerns (as Measured by the Illness-related Phobia Subscale)

\begin{tabular}{|c|c|c|c|c|c|c|c|c|}
\hline Equation $^{(1)}$ & Predictor & DV & $\beta$ & $t$ & $p$ & $R^{2}$ & $F_{(d f)}$ & Sobel test $(p)$ \\
\hline 1.1 & ASI- total score & PAS-Illness Phobia & .650 & 5.808 & .000 & .41 & $33.732_{(1,46)}{ }^{* *}$ & $2.104(.035)$ \\
\hline \multirow[t]{2}{*}{1.3} & ASI-total score & Panic & .136 & .792 & $n s$ & .20 & $6.915_{(2,45)} *$ & \\
\hline & PAS-Illness Phobia & & .385 & 2.245 & .030 & & & \\
\hline 2.1 & ASI-Physical Concerns & PAS-Illness Phobia & .671 & 6.138 & .000 & .43 & $37.681_{(1,46)}{ }^{* *}$ & $2.180(.029)$ \\
\hline \multirow[t]{2}{*}{2.3} & ASI-Physical Concerns & Panic & .093 & .528 & $n s$ & .19 & $6.691_{(2,45)} *$ & \\
\hline & PAS-Illness Phobia & & .411 & 2.329 & .024 & & & \\
\hline 3.1 & ASI-Mental Concerns & PAS-Illness Phobia & .476 & 3.675 & .001 & .21 & $13.502_{(1,46)} * *$ & $2.081(.037)$ \\
\hline \multirow[t]{2}{*}{3.3} & ASI-Mental Concerns & Panic & .223 & 1.529 & $n s$ & .23 & $8.018_{(2,45)}{ }^{* *}$ & \\
\hline & PAS-Illness Phobia & & .368 & 2.526 & .015 & & & \\
\hline 4.1 & ASI-Social Concerns & PAS-Illness Phobia & .369 & 2.692 & .010 & .11 & $7.246_{(1,46)^{*}}$ & $2.130(.033)$ \\
\hline \multirow[t]{2}{*}{4.3} & ASI-Social Concerns & Panic & .040 & .286 & $n s$ & .19 & $6.564_{(2,45)} *$ & \\
\hline & PAS-Illness Phobia & & .489 & 3.463 & .001 & & & \\
\hline
\end{tabular}

Note. ${ }^{(1)}$ The second equation for each set of analyses was presented in Table 2.

DV: dependent variable in the equation; ASI: Anxiety Sensitivity Index; PAS: Panic Agoraphobic Spectrum.

$* p \leq .01 . * * p \leq .001$. 


\section{Discussion}

Consistently with previous research (Furer et al., 1997; Maller \& Reiss, 1992; Messenger \& Shean, 1998; Schmidt et al., 1997, 1999), the results of this study support the hypothesis that both hypochondriacal concerns and anxiety sensitivity features predict panic symptomatology. The results also indicate that anxiety sensitivity, in turn, is related to hypochondriacal concerns (Bravo \& Silverman, 2001; Otto et al., 1992, 1998; Watt \& Stewart, 2000). Although these relationships have been previously documented, the precise nature of the relations among the three variables is not yet well understood or widely agreed upon. This study brings some preliminary evidence of the specific pattern of interrelationships between anxiety sensitivity and hypochondriacal beliefs to affect the development of panic.

Consistently with the hypothesis, the effect of anxiety sensitivity on panic symptomatology was not significant when controlling hypochondriacal concerns, whereas the latter predicted panic symptoms. This was true for the overall ASI as well as for the Physical Concerns and the Mental Incapacitation Concerns dimensions. However, no evidence of a direct relation between the Social Concerns dimension of the ASI and panic symptoms was found. Nevertheless, the relation between the Social Concerns dimension and panic is also unclear in previous studies in comparison to the contribution of the other dimensions to fear responses (Schmidt et al., 1999; Zinbarg et al., 2001; Zvolensky, Goodie, McNeil, Sperry, \& Sorrell, 2001).

It is noteworthy that when the data analyses were repeated with alternative measures of the mediator variable, all major findings were replicated. Therefore, the results of this study indicate that the effects of anxiety sensitivity and hypochondriacal fears on panic are not independent. In contrast, the findings support a mediational role for hypochondriacal concerns in the relation between the overall ASI and two of its dimensions and panic.

Previous research has suggested that anxiety sensitivity may contribute to the development of hypochondriacal concerns (Bravo \& Silverman, 2001; Otto et al., 1992, 1998; Watt \& Stewart, 2000). As Watt and Stewart (2000) noted, instrumental and vicarious learning experiences (i.e., parental reinforcement, modeling, etc.) that tend to catastrophize about the occurrence of bodily symptoms in general, rather than anxiety-related symptoms in particular, might lead to the development of higher-than-normal levels of anxiety sensitivity that, in turn, might elicit or instigate hypochondriacal concerns. From the same perspective, Cox, Fuentes, Borger, and Taylor (2001) suggested that the anxiety sensitivity trait might extend to a broader catastrophic style concerning bodily symptoms and health that go beyond anxiety symptoms per se.

The findings in this study suggest that such hypochondriacal concerns might represent one of the psychological mechanisms through which the anxiety sensitivity dimensions are able to influence panic symptomatology. Hypochondriacal concerns significantly decrease the effect of anxiety sensitivity, indicating that they might indeed represent a potent mediator. Nevertheless, hypochondriacal concerns did not completely eliminate the effect of anxiety sensitivity, suggesting that although powerful, anxiety sensitivity is neither a necessary nor a sufficient condition for panic to occur. That is, findings in this study also suggest that additional mediating factors may operate between anxiety sensitivity and panic.

These findings of how or why anxiety sensitivity affects panic symptoms may be of great importance at the practical level. They suggest that interventions to prevent panicagoraphobic disorders might be oriented to prevent anxiety sensitivity from having adverse effects, such as eliciting hypochondriacal concerns. Additionally, the findings of this study suggest that the occurrence of hypochondriacal concerns should be appraised within the psychological assessment process of panic-agoraphobic disorders, and accordingly treated when it is of psychological significance.

Several limitations of this study should be pointed out. First, the study follows a cross-sectional design presuming, according to previous research, that the criterion does not predict the mediator, and that the latter does not predict the independent variable. Future research to test such relationships, and additional feedback or transactional models through longitudinal methodologies and statistical procedures, such as structural equation modeling, should be carried out. Second, the study used a small clinical sample, thereby restricting the range of both anxiety sensitivity and the outcome measures. Additional studies with more diverse and larger samples should be carried out. Finally, as Baron and Kenny (1986) highlighted, multiple independent and converging measurements are required to reveal the construct validity of a mediation model. Thus, further research using multiple indicator approaches is needed to test the proposed model.

\section{References}

American Psychiatric Association (2000). Diagnostic and statistical manual of mental disorders (4 ${ }^{\text {th }}$ ed., text rev.). Washington, DC: Author.

Baron, R.M., \& Kenny, D.A. (1986). The moderator-mediator variable distinction in social psychological research: Conceptual, strategic, and statistical considerations. Journal of Personality and Social Psychology, 51, 1173-1182.

Berrocal, C., Ruiz Moreno, M., Gil Villa, M., Hermoso, P., Rucci, P., \& Cassano, G.B. (2006). Multidimensional assessment of the Panic-Agoraphobic Spectrum: Reliability and validity of the Spanish version of the PAS-SR. Journal of Anxiety Disorders, 20, 562-579.

Bravo, I.M., \& Silverman, W.K. (2001). Anxiety sensitivity, anxiety, and depression in older patients and their relation to 
hypochondriacal concerns and medical illnesses. Aging and Mental Health, 5, 349-357.

Cassano, G.B., Banti, S., Mauri, M., Dell'Osso, L., Miniati, M., Maser, J.D., Shear, M. K., Frank, E., Grochocinski, V., \& Rucci P. (1999). Internal consistency and discriminant validity of the Structured Clinical Interview for Panic-Agoraphobic Spectrum (SCI-PAS). International Journal of Methods in Psychiatric Research, 8, 138-145.

Cox, B.J., Fuentes, K., Borger, S.C., \& Taylor, S. (2001). Psychopathological correlates of anxiety sensitivity: Evidence from clinical interviews and self-report measures. Journal of Anxiety Disorders, 14, 317-332.

Fava, G.A., Grandi, S., \& Canestrari, R. (1988). Prodromal symptoms in panic disorder with agoraphobia. American Journal of Psychiatry, 145, 1564-1567.

Fava, G.A., Grandi, S., Rafanelli, C., \& Canestrari, R. (1992). Prodromal symptoms in panic disorder with agoraphobia: A replication study. Journal of Affective Disorders, 26, 85-88.

Feske, U., Frank, E., Mallinger, A.G., Houck, P.R., Fagiolini, A., \& Shear, M.K. (2000). Anxiety as a correlate of response to the acute treatment of bipolar I disorder. American Journal of Psychiatry, 157, 956-962.

Frank, E., Cyranowski, J.M., Rucci, P., Shear, M.K., Fagiolini, A., Thase, M.E., Cassano, G.B., Grochocinski, V.J., Kostelnik, B., \& Kupfer, D.J. (2002). Clinical significance of lifetime panic spectrum symptoms in the treatment of patients with bipolar I disorder. Archives of General Psychiatry, 59, 905911.

Frank, E., Shear, M.K., Rucci, P., Cyranowski, J.M., Endicott, J., Fagiolini, A., Grochocinski, V.J., Houck, P., Kupfer, D.J., Maser, J.D., \& Cassano, G.B. (2000). Influence of panic-agoraphobic spectrum symptoms on treatment response in patients with recurrent major depression. American Journal of Psychiatry, 157, 1101-1107.

Furer, P., Walker, J.R., Chartier, M.J., \& Stein, M.B. (1997). Hypochondriacal concerns and somatization in panic disorder. Depression and Anxiety, 6, 78-85.

Keller, M.B., Yonkers, K.A., Warshaw, M.G., Pratt, L.A., Gollan, J.K., Massion, A.O., White, K., Swartz, A.R., Reich, J., \& Lavori, P.W. (1994). Remission and relapse in subjects with panic disorder and panic with agoraphobia: A prospective shortinterval naturalistic follow-up. The Journal of Nervous and Mental Disease, 182, 290-296.

MacKinnon, D.P. (1994). Analysis of mediating variables in prevention and intervention research. In A. Cazares \& L.A. Beatty (Eds.), Scientific methods in prevention research. NIDA Research Monograph 139 (pp. 127-153). Washington, DC: U.S. Government Printing Office.

Maller, R.G., \& Reiss, S. (1992). Anxiety sensitivity in 1984 and panic attacks in 1987. Journal of Anxiety Disorders, 6, 241247.

Messenger, C., \& Shean, G. (1998). The effects of anxiety sensitivity and history of panic on reactions to stressors in a non clinical sample. Journal of Behavior Therapy and Experimental Psychiatry, 29, 279-288.
Noyes, R., Woodman, C.L., Bodkin, J.A., \& Yagla, S.J. (2004). Hypochondriacal concerns in panic disorder and major depressive disorder: A comparison. The International Journal of Psychiatry in Medicine, 2, 143-154.

Otto, M.W., Demopulos, C.M., McLean, N.E., Pollack, M.H., \& Fava, M. (1998). Additional findings on the association between anxiety sensitivity and hypochondriacal concerns: Examination of patients with major depression. Journal of Anxiety Disorders, 12, 225-232.

Otto, M.W., Pollack, M.H., Sachs, G.S., \& Rosenbaum, J.F. (1992). Hypochondriacal concerns, anxiety, sensitivity, and panic disorder. Journal of Anxiety Disorders, 6, 93-104.

Perugi, G., Toni, C., Benedetti, A., Simonetti, M., Torti, C., Musetti, L., \& Akiskal, H.S. (1998). Delineating a putative phobicanxious temperament in 126 panic-agoraphobic patients. Journal of Affective Disorders, 47, 11-23.

Peterson, R.A., \& Heilbronner, R.L. (1987). The Anxiety Sensitivity Index: Construct validity and factor analytic structure. Journal of Anxiety Disorders, 2, 117-121.

Peterson, R.A., \& Reiss, S. (1992). Anxiety Sensitivity Index Manual ( $2^{\text {nd }}$ ed.). Worthington, OH: International Diagnostic Systems.

Pilowsky, I. (1967). Dimensions of hypochondriasis. British Journal of Psychiatry, 113, 89-93.

Reiss, S. (1987). Theoretical perspectives on the fear of anxiety. Clinical Psychology Review, 7, 585-596.

Reiss, S. (1991). Expectancy model of fear, anxiety, and panic. Clinical Psychology Review, 11, 141-153.

Reiss, S., Peterson, R.P., Gursky, D.M., \& McNally, R.J. (1986). Anxiety sensitivity, anxiety frequency, and the prediction of fearfulness. Behaviour Research and Therapy, 24, 1-8.

Sandín, B., Chorot, P., \& McNally, R.J. (1996). Validation of the Spanish version of the Anxiety Sensitivity Index in a clinical sample. Behaviour Research and Therapy, 34, 283-290.

Schmidt, N.B., Lerew, D.R., \& Jackson, R.J. (1997). The role of anxiety sensitivity in the pathogenesis of panic: Prospective evaluation of spontaneous panic attacks during acute stress. Journal of Abnormal Psychology, 106, 355-364.

Schmidt, N.B., Lerew, D.R., \& Jackson, R.J. (1999). Prospective evaluation of anxiety sensitivity in the pathogenesis of panic: Replication and extension. Journal of Abnormal Psychology, 108, 532-537.

Shear, M.K., Frank, E., Rucci, P., Fagiolini, A., Grochocinski, V., Houck, P., Cassano, G.B., Kupfer, D.J., Endicott, J., Maser, J., Mauri, M., \& Banti, S. (2001). Panic-agoraphobic spectrum: Reliability and validity of assessment instruments. Journal of Psychological Research, 35, 59-66.

Sobel, M.E. (1990). Effect analysis and causation in linear structural equation models. Psychometrika, 55, 495-515.

Speckens, A.E.M., Spinhoven, P., \& Sloekers, P.P.A. (1996). A validation study of the Whiteley Index, the Illness Attitude Scales and the Somatosensory Amplification Scale in general medical and general practice patients. Journal of Psychosomatic Research, 40, 95-104.

Speckens, A.E.M. (2001). Assessment of hypochondriasis. In V. Starcevic \& D.R. Lipsitt (Eds.), Hypochondriasis: Modern 
perspectives on an ancient malady (pp. 61-88). New York: Oxford University Press.

Taylor, S., \& Cox, B.J. (1998). Anxiety sensitivity: Multiple dimensions and hierarchic structure. Behaviour Research and Therapy, 36, 37-51.

Taylor, S., Koch, W.J., \& McNally, R.J. (1992). How does anxiety sensitivity vary across the anxiety disorders? Journal of Anxiety Disorders, 6, 249-259.

Watt, M.C., \& Stewart, S.H. (2000). Anxiety sensitivity mediates the relationships between childhood learning experiences and elevated hypochondriacal concerns in young adulthood. Journal of Psychosomatic Research, 49, 107-118.

World Health Organization (1992). International Classification of Diseases (10 ${ }^{\text {th }}$ revision). Geneva: Author.

Zinbarg, R.E., Brown, T.A., \& Barlow, D.H. (1997). Hierarchical structure and general factor structure saturation of the Anxiety
Sensitivity Index: Evidence and implications. Psychological Assessment, 9, 277-284.

Zinbarg, R.E., Brown, T.A., Barlow, D.H., \& Rapee, R.M. (2001). Anxiety sensitivity, panic, and depressed mood: A reanalysis teasing apart the contributions of the two levels in the hierarchical structure of the anxiety sensitivity index. Journal of Abnormal Psychology, 110, 372-377.

Zvolensky, M.J., Goodie, J.L., McNeil, D.W., Sperry, J.A., \& Sorrell, J.T. (2001). Anxiety sensitivity in the prediction of pain-related fear and anxiety in a heterogeneous chronic pain population. Behaviour Research and Therapy, 39, 683696.

Received February 22, 2006 Review received November 29, 2006 Accepted February 19, 2007 